\title{
Autologous Corneal Transplant from an Enucleated Fellow Eye for Choroidal Melanoma: A Case Report
}

\author{
Matias Iglicki ${ }^{a} \quad$ Anat Loewenstein $^{b} \quad$ Manuel Manera $^{c} \quad$ Claudia Castro $^{c}$ \\ Catharina Busch $^{d}$ Dinah Zur ${ }^{b}$ Hermino Pablo Negric \\ aprivate Retina Office, University of Buenos Aires, Buenos Aires, Argentina; \\ ${ }^{b}$ Ophthalmology Division, Tel Aviv Medical Center affiliated to the Sackler Faculty of \\ Medicine, Tel Aviv University, Tel Aviv, Israel; 'Diagnostic Ophthalmology Center, Buenos \\ Aires, Argentina; dUniversity Hospital Leipzig Department of Ophthalmology, \\ Leipzig, Germany
}

\section{Keywords}

Homonymous corneal graft · Choroidal melanoma $\cdot$ Enucleation

\begin{abstract}
Background: To report a case of autologous corneal transplant in a patient with corneal leukoma and choroidal melanoma in the fellow eye. Case Presentation: A 56-year-old woman was complaining about decrease in vision in her left eye. The patient was on the waiting list for a corneal transplant on her right eye due to corneal leucoma after a previous herpes infection. The patient was diagnosed with choroidal melanoma in her left eye. Due to the tumor size (longitudinal diameter $>10 \mathrm{~mm}$; anterior-posterior diameter $>16 \mathrm{~mm}$ ) the patient decided to undergo enucleation, after being informed about different treatment options (brachytherapy and enucleation). The patient showed her willingness to use the cornea of the left eye as a transplant for her right eye. After discussion with the ethical committee and its approval, and signing informed consent, the patient underwent enucleation of her left eye. The sample was examined by a pathologist and found to be free of melanoma cells in the corneolimbal tissue. Afterwards, trepanation of the donor cornea button was performed and transplanted to the left eye. Conclusion: Autologous corneal transplantation is a safe and feasible procedure in selected cases.




\section{Background}

Choroidal melanomas are the most common primary malignancy of the eye, with an annual incidence of 6 cases per 1 million population $[1,2]$. It is more common in Caucasian adults and rare in dark-skinned or children. Predisposing factors for choroidal melanoma include light eye color, fair skin color, ocular melanocytosis, and preexisting nevi, even the incidence of malignancy conversion is very low [3].

Enucleation is appropriate for large melanomas in which the vision is compromised if more conservative treatments are used and also if the tumor surrounds or invades the optic nerve head. Enucleation is recommended when the tumor is classified as medium (longitudinal diameter 2.5-10 $\mathrm{mm}$, anterior-posterior diameter $<16 \mathrm{~mm}$ ) and large in size (longitudinal diameter $>10 \mathrm{~mm}$; anterior-posterior diameter $>16 \mathrm{~mm}$ ) [4].

The cornea is an avascular tissue covered anteriorly by a multilayer stratified, nonkeratinized epithelium. This epithelium is constantly regenerated by limbal stem cells, a unique cell population located in the basal epithelial layer of the corneal limbus (the corneo-conjunctival junction). The corneal stroma is an avascular collagenous layer with a very poor propensity for neoangiogenesis. Hence, before this case, there were no special restrictions on obtaining ocular tissues for transplantation from donors with metastatic uveal melanoma. Donors with systemic solid tumor malignancies have been eligible for ocular tissue transplantation. These donors may constitute upwards of $30-40 \%$ of the donor pool [5, 6].

Wagoner et al. [5] performed a long-term retrospective analysis of 73 patients who received corneal donor material from donors who died from various systemic malignancies. They found no increased incidence of malignancy or earlier mortality in the recipient population, and no patient developed local tumor growth.

López-Navidad at al. [6] performed histopathological evaluation of the remaining corneoscleral rim in 408 donor eyes from donors with an active malignancy or history of malignancy after the donor button was removed and transplanted. There was no tumor transmission in any of the 325 recipients.

All these reasons have led the ethical committee to the conclusion that homonymous corneal transplant from an enucleated fellow eye for choroidal melanoma is a safe procedure.

\section{Case Presentation}

A 56-year-old woman was complaining about decrease in vision on her left eye.

Prior ocular history involved corneal leucoma on her right eye due to a previous herpes infection (Fig. 1). She was currently on the waiting list for a corneal transplantation.

At the ophthalmologic emergency unit, she was diagnosed with a retinal detachment due to an intraocular mass in her left eye (Fig. 2). She was sent immediately to the retinal division where ultrasound, ocular biomicroscopy, and wide-field photography were performed (Fig. 2). Best-corrected visual acuity (BCVA) was 20/80 on her right eye and 20/200 on her left eye. Intraocular pressure was $14 \mathrm{~mm} \mathrm{Hg}$ in her right eye and $17 \mathrm{~mm} \mathrm{Hg}$ in her left eye. The right cornea was opaque due to leucoma (Fig. 1). Ocular examination of the left eye revealed an elevated pigmentary choroidal tumor, covering the temporal half of the fundus and accompanied by an exudative retinal detachment involving the macula (Fig. 2). B-scan ultrasound confirmed the presence of a choroidal melanoma, showing medium internal reflectivity on Amode and large size (longitudinal diameter $>10 \mathrm{~mm}$; anterior-posterior diameter $>16 \mathrm{~mm}$ ). General oncology screening ruled out systemic dissemination. Macular optical coherence 
tomography (OCT; Cirrus HD-OCT, Zeiss, Germany) showed a smooth dome-shaped choroidal elevation compatible with choroidal melanoma and associated retinal detachment. Due to the large tumor size, the patient decided to undergo enucleation, after being informed about different treatment options (brachytherapy and enucleation). The patient showed her willingness to use the cornea of the left eye as a transplant for her right eye. After discussion with the ethical committee, its approval, and signing informed consent, the patient underwent enucleation of her left eye (Fig. 3). The enucleated sample was examined by a pathologist and found to be free of melanoma cells in the corneolimbal tissue. Afterwards, trepanation of the donor cornea button was performed, and the cornea was transplanted to the right eye (Fig. 4).

The patient has been followed for over 60 days without any sign of corneal transplant rejection, and her left eye was according to the enucleation protocol. BCVA in her right eye improved to 20/40 (Fig. 5).

\section{Discussion and Conclusion}

This is the first case report showing the feasibility and safety of homonymous corneal transplantation in a patient with choroidal melanoma. After discussing all treatment options with the patient, we decided together to enucleate the left eye due to the tumor size. Since our patient was also in need of a corneal transplant for her fellow eye, we safely performed autologous corneal transplantation. As it has been published previously, the risk for tumor transmission by corneal transplant is very low $[5,6]$, and close long-term follow-up is indicated. Therefore, it can be considered in suitable patients. Moreover, in these extremely rare cases where autologous transplantation presents a viable option for the patient, we suggest performing both surgeries in the same session in order to avoid additional general anesthesia and also to decrease patients' anxiety.

Notably, these cases could be diagnosed in patients of every age. Therefore, we strongly believe that this technique should be considered in cases with enucleated eye and any indication of corneal graft in the fellow eye, i.e. leucoma, extreme keratoconus, or hydrops.

In conclusion, we recommend to consider autologous corneal transplant from an enucleated fellow eye for choroidal melanoma if there is a need to use clear cornea in this kind of condition, and allow the patient to shorten the waiting period on the transplant list for a corneal graft in their only eye.

\section{Statement of Ethics}

This study was conducted ethically in accordance with the World Medical Association Declaration of Helsinki. The subject has given written informed consent to publish this case.

\section{Disclosure Statement}

The authors declare that they have no competing interests. 
Funding Sources

No funding or grant support.

\section{Author Contributions}

M.I., M.M., and H.P.N. analyzed and interpreted the patient data regarding the choroidal melanoma disease and the corneal graft. C.C. performed the enucleation and was a major contributor in writing the manuscript. D.Z., M.I., C.B., and A.L., wrote and reviewed the study. D.Z., M.I., and C.B. were also involved in data acquisition. All authors read and approved the final manuscript.

\section{References}

1 Shields CL, Manalac J, Das C, Ferguson K, Shields JA. Choroidal melanoma: clinical features, classification, and top 10 pseudomelanomas. Curr Opin Ophthalmol. 2014 May;25(3):177-85.

2 Scotto J, Fraumeni JF Jr, Lee JA. Melanomas of the eye and other noncutaneous sites: epidemiologic aspects. J Natl Cancer Inst. 1976 Mar;56(3):489-91.

3 Shields CL, Kaliki S, Furuta M, Mashayekhi A, Shields JA. Clinical spectrum and prognosis of uveal melanoma based on age at presentation in 8,033 cases. Retina. 2012 Jul;32(7):1363-72.

4 The Collaborative Ocular Melanoma Study (COMS) randomized trial of pre-enucleation radiation of large choroidal melanoma III: local complications and observations following enucleation COMS report no. 11. Am J Ophthalmol. 1998 Sep;126(3):362-72.

5 Wagoner MD, Dohlman CH, Albert DM, Lavin P, Murphy A, O'Neill-Dryja M. Corneal donor material selection. Ophthalmology. 1981 Feb;88(2):139-45.

6 López-Navidad A, Soler N, Caballero F, Lerma E, Gris 0. Corneal transplantations from donors with cancer. Transplantation. 2007 May;83(10):1345-50. 


\section{Case Reports in Ophthalmology} www.karger.com/cop

Iglicki et al.: Autologous Corneal Transplant from an Enucleated Fellow Eye for Choroidal Melanoma: A Case Report

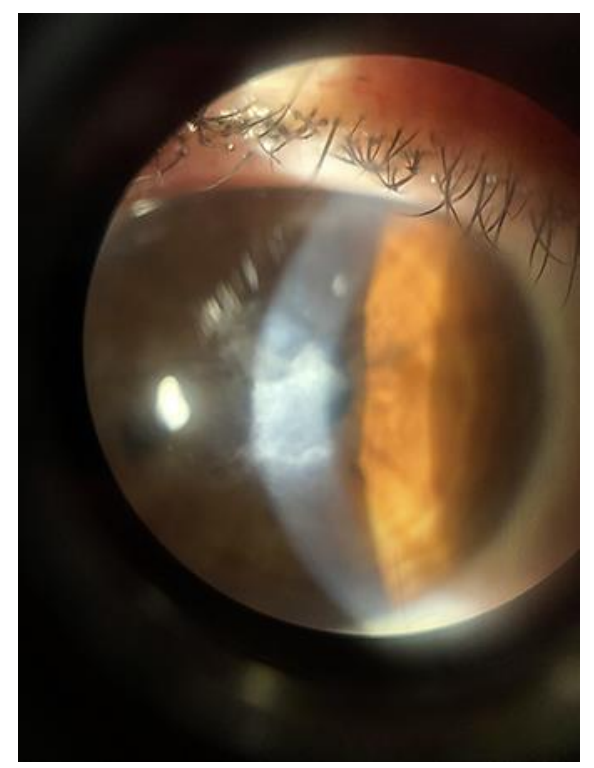

Fig. 1. Slit lamp picture of the right eye showing corneal leucoma after herpes infection.

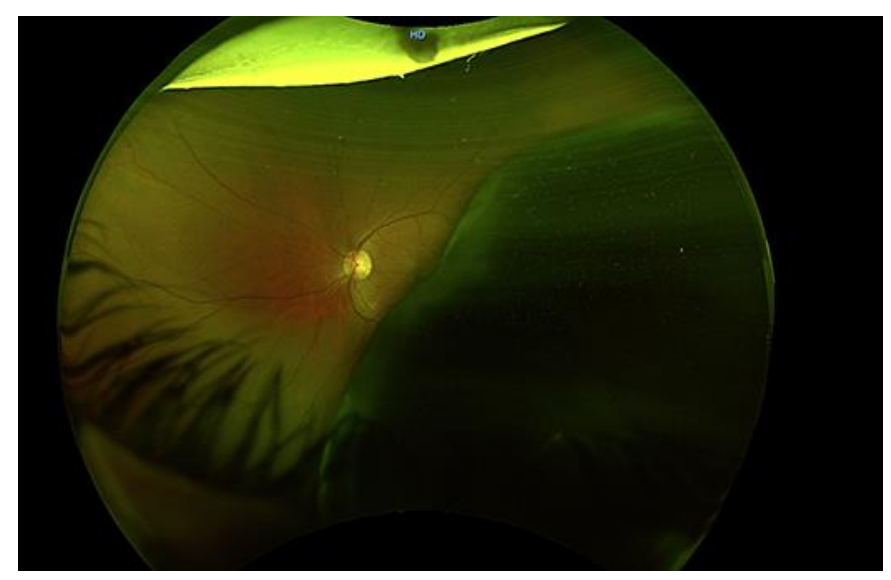

Fig. 2. Widefield fundus picture of the left eye showing a large pigmentary choroidal melanoma. 


\section{Case Reports in Ophthalmology}

\begin{tabular}{l|l}
\hline Case Rep Ophthalmol 2020;11:181-188 \\
\hline DOI: 10.1159/000507776 & $\begin{array}{l}\text { ○ 2020 The Author(s). Published by S. Karger AG, Basel } \\
\text { www.karger.com/cop }\end{array}$ \\
\hline
\end{tabular}

www.karger.com/cop

Iglicki et al:: Autologous Corneal Transplant from an Enucleated Fellow Eye for Choroidal Melanoma: A Case Report

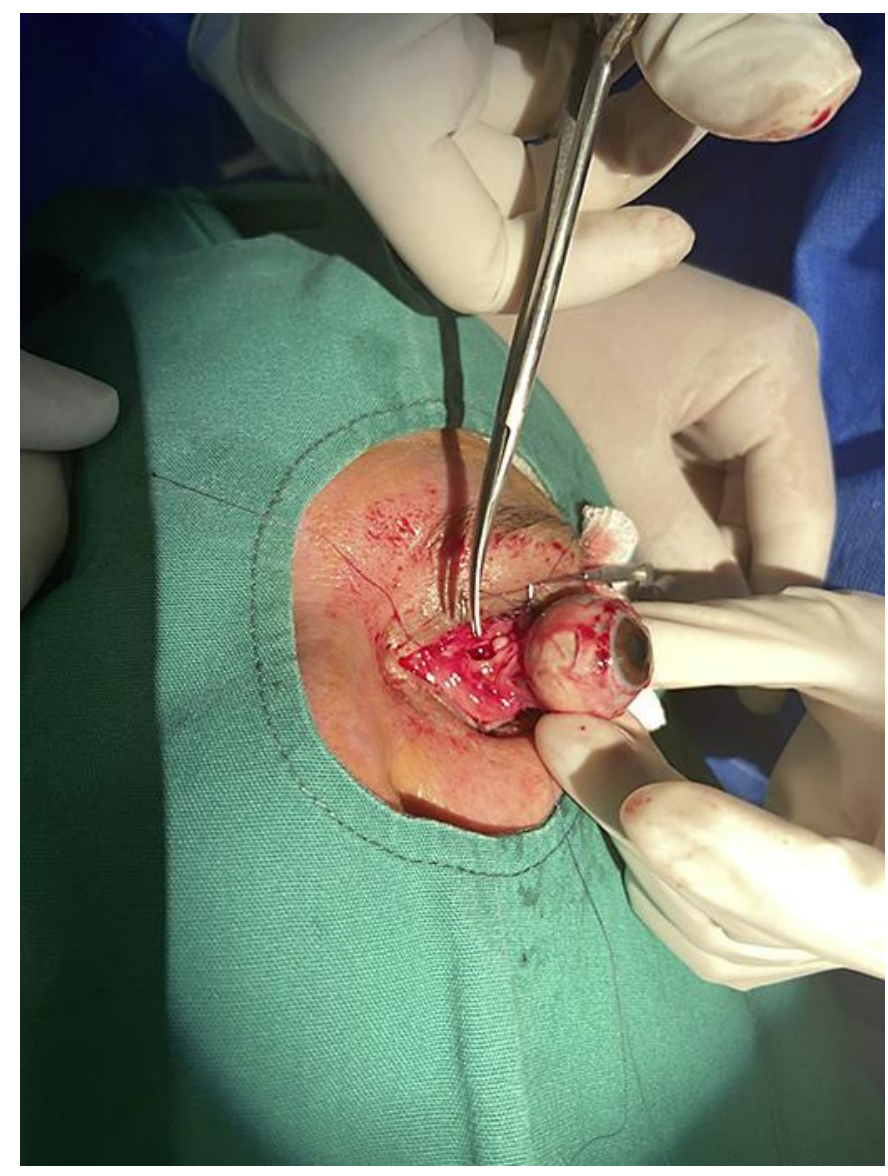

Fig. 3. Intraoperative picture showing enucleation procedure of the left eye. 


\section{Case Reports in Ophthalmology}

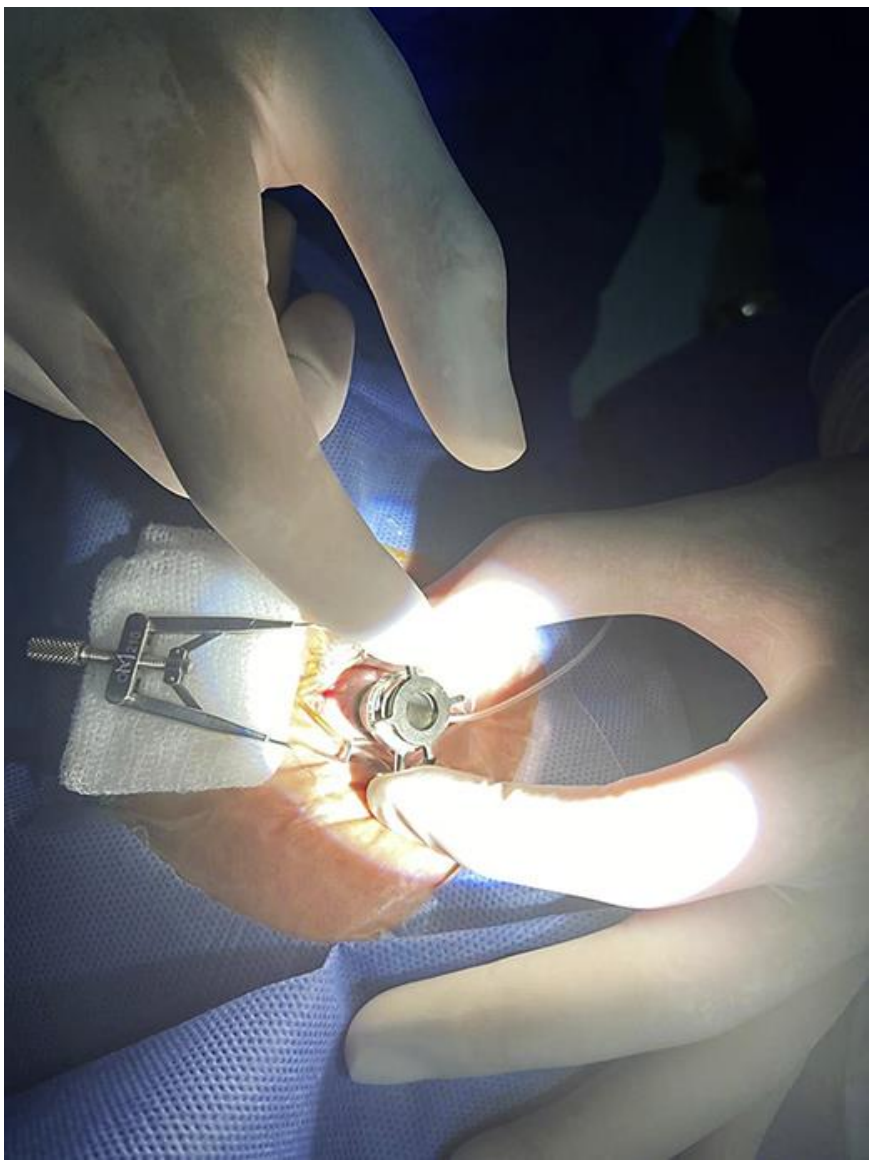

Fig. 4. Intraoperative picture showing trepanation of the donor cornea.

Iglicki et al.: Autologous Corneal Transplant from an Enucleated Fellow Eye for Choroidal Melanoma: A Case Report 

www.karger.com/cop

Iglicki et al.: Autologous Corneal Transplant from an Enucleated Fellow Eye for Choroidal Melanoma: A Case Report

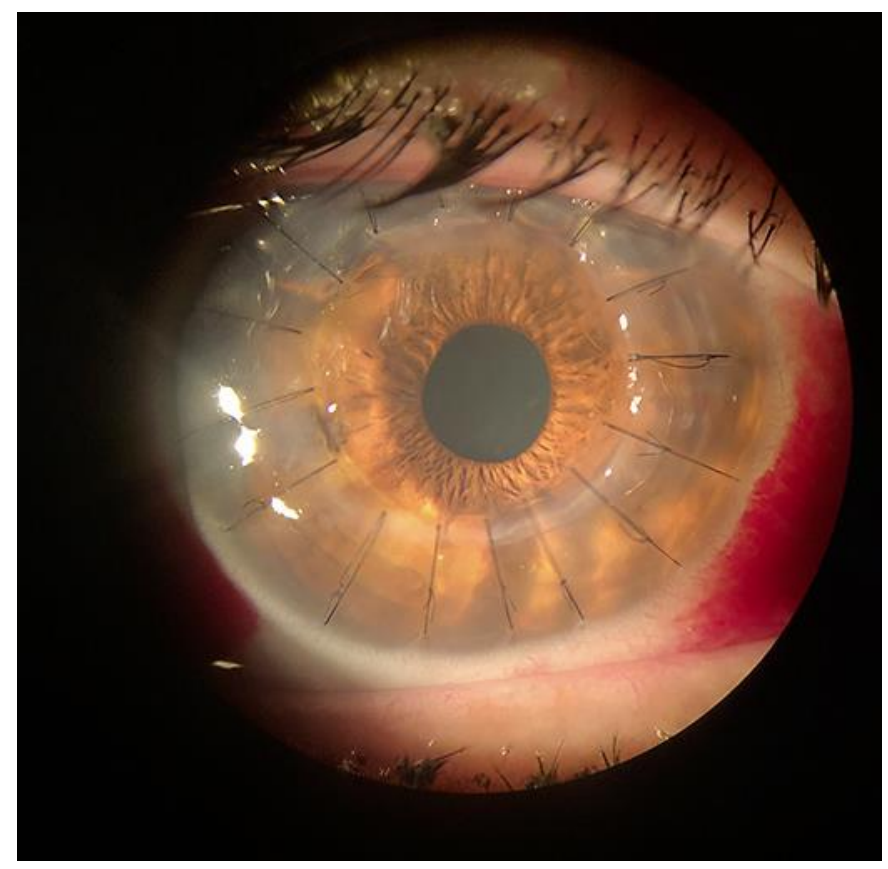

Fig. 5. Slit lamp picture of the right eye showing a clear corneal transplant. 